\title{
Innovation of Enterprise Human Resource Performance Management in Big Data Era
}

\author{
Wei wei, Mengge Li \\ School of economics and management, College of Beijing Jiao tong University \\ Haidian district, Beijing, 100044, China \\ 1033566691@qq.com \\ Mengge Li
}

Keywords: Big Data, Performance Management, Innovation

\begin{abstract}
Talents are the core competitiveness of enterprises, and performance management is the core link of human resource management. With the continuous improvement of the socialist market economy in China, the problems in the performance management of enterprises are gradually exposed. The arrival of the era of big data makes the use of big data to carry out human resource performance management become a mainstream trend, and the application of big data technology to performance management improve the efficiency and effect of human resource management. Based on the background of big data, this paper analyzes the current situation and existing problems of human resource performance management, and looks forward to its innovation path, in order to provide some ideas for the innovation of performance management.
\end{abstract}

\section{Introduction}

Peter Drucker, the father of modern management, once proposed that the most effective management method for managers lies in performance management. Human resources management in the era of big data can make up for the disadvantages of the traditional extensive human resources management mode by analyzing a large number of actual operating data. Under the background of big data era, performance management, which is the core part of human resources management module, must formulate and effectively implement human resources strategies more scientifically and give timely feedback if it is to truly become an effective tool for formulating strategies and strategies. The realization of this state must be based on objective analysis of business data and reasonable performance index setting. Based on this, improving and innovating the human resource performance management level in the era of big data is a problem that enterprises and managers must pay attention to.

\section{Characteristics of Performance Management Based on Big Data}

(1) Openness of Performance Data

On the one hand, performance data openness refers to the openness of data providers, which is conducive to the collection of more and more comprehensive data in the company's database. On the other hand, it refers to opening up to data users. On the one hand, the biggest advantage is to reduce the company's cost in collecting data to obtain information, speed up the decision-making speed and accuracy, improve the efficiency of various departments, and at the same time make performance information transparent. Employees can carry out self-supervision and mutual encouragement according to their own and other people's performance data.

(2) Real-time Synchronization of Performance Data

Big data technology can record and store all kinds of behavior data of employees in real time and for a long time, which has the effect of supervising the performance of employees. Objectivity of data and meticulous management can improve the objectivity of performance management. At the same 
time, because the data are stored through the database, the loss of data can be effectively avoided through backup, thus ensuring the integrity of personal information.

(3) Visualization of Performance Evaluation Image

Data processing technology combined with human-computer interaction makes data evaluation more in-depth. Due to the integrity of data, managers can analyze the relationship between behavior performance and process performance, obtain more performance control nodes from data, and visualize the hidden logical relationship between data. At the same time, big data technology analyzes the same data from multiple angles and interprets the information contained in the data in different forms to meet the needs of different users.

(4) Diversification of Performance Management Positions

The application of big data to enterprises has promoted the creation of many new positions, such as: chief data officer, data scientists, data analysts, etc. Their main responsibilities are to manage the data resources generated inside the enterprise or acquired from outside, which are already owned by the enterprise, and to obtain the data resources needed by the enterprise through various channels, and to mine, analyze and use these data to create value for the enterprise. Faced with the complex and diverse performance management data of enterprises, human resources departments need not analyze and interpret them, but simply collect and extract them, so that they will jump out of the repetitive and inefficient performance management tasks in the past.

\section{Problems in performance management}

(1) Lack of scientific assessment index system

China's market economy started relatively late. In small and medium-sized enterprises, the experience of implementing human resource management and performance management is very insufficient. Compared with Western countries, the lack of advanced performance management concepts often leads to managers failing to formulate scientific and reasonable performance appraisal. System, at present, the performance appraisal system in China's small and medium-sized enterprises is mainly reflected in three aspects: the evaluation indicators are too fine; the blind pursuit of quantification, the indicators that cannot be quantified are often neglected; the assessment is too frequent, and the employees' work enthusiasm is combated.

(2) Managers do not pay attention to performance feedback

Managers of many small-scale enterprises in China tend to confuse performance appraisal and performance management, focusing only on the appraisal process, and failing to provide feedback on performance results and employee management after the appraisal. The purpose of performance appraisal is to supervise employees, find problems and correct them in time to improve the efficiency of the whole enterprise. If there is no timely feedback and communication after the assessment, let the employees know their own problems, and do not conduct corresponding tracking and investigation. Then the whole assessment is meaningless.

(3) Poor innovation environment for performance appraisal

At present, in the human resources management of state-owned enterprises in our country, performance appraisal lacks a good innovation environment. At the same time, some enterprises have not carried out information construction or lack of information construction in human resources management. Management systems and methods are still relatively backward and cannot update and share work information and work completion in real time, which leads to inaccuracies and flaws in information in performance management and makes it difficult to carry out assessment work smoothly [9].

(4) Data security risks

In an open network environment, the leakage of company data, especially core data, is an extremely serious problem, which will bring huge economic losses to the company. In the company's internal staff information-intensive human resources department, whether it is the information of the incumbent, or the recruitment process, the basic information submitted by the applicant, if the company is not properly managed, will lead to the loss of talent. 


\section{Innovative Approaches to Performance Management}

\subsection{Enhance the application of big data in performance management}

The application of big data in performance management can be improved from two aspects, one is to update people's ideas. First of all, managers should be aware of the convenience and low cost that big data can bring, recognize the current situation and take the initiative to use big data to improve the shortcomings of traditional performance management, and make bold innovations in performance management in light of the requirements of the development of the times; On the other hand, it is to strengthen the construction of data platforms, increase the timeliness and pertinence of data information, and make information more comprehensive and smooth. While ensuring sharing, it must ensure data security and data leakage cannot occur.

\subsection{Improve the personal qualities and abilities of performance managers}

In order to improve the efficiency of performance management, enterprises should comprehensively train performance managers to better understand performance management concepts, contents, methods and methods, and formulate different assessment standards for different talents to improve the effectiveness and pertinence of performance management; In the training process, the manager's behavior and performance data should be recorded, the data summary rules should be accumulated, and the characteristics of different managers should be found according to the data, which has very important guiding significance for the employees' personal development in the future.

\subsection{Establish a scientific and perfect performance appraisal system}

(1) Formulating reasonable quantitative targets

The first step in formulating the performance appraisal system is to determine the appraisal criteria. The goal setting should be reasonable. We should not pay too much attention to the quantitative form. In the process of performance management, we fully consider the characteristics of the era data and adhere to the important criteria of maximizing benefits. The rules of daily behavior and personal quality data adhere to the principle of objectivity, the goal is necessary, and rational quantification is even more crucial.

(2) Improve assessment methods and processes

On the basis of the one-year overall performance appraisal, adhere to appropriate and irregular performance appraisal. In the annual comprehensive assessment, the overall performance and the results of the non-periodic performance evaluation are evaluated as comprehensive criteria; according to the multi-angle analysis of big data, employees are evaluated from multiple dimensions; and the performance of employees is measured by using big data technologies such as HRMS technology. The results are compared with the KPI and the results are automatically matched.

(3) Do a good job of performance feedback, pay attention to the career development plan of employees

First of all, after the end of the assessment work, the performance evaluation results based on big data should be carefully analyzed. Through the data platform, the assessed persons can understand the gap between their performance and organizational expectations, and give the examinee a chance to explain or improve, so as to pass the assessment. It is an incentive and spur to the person being assessed. Use big data technology to aggregate the overall data of employees, generate employee growth curve, so that employees can better understand themselves, rationally position and principles, and promote personal career development.

\section{Conclusion and Prospect}

Based on the development of the Internet and the advent of the era of big data, this paper deeply analyzes the current situation of performance management in small and medium-sized enterprises in China and elaborates many existing problems. In the application of big data to performance management innovation, this paper puts forward suggestions from three aspects: improving the application of big data, improving the quality of performance managers, and establishing a perfect 
performance management system, so as to provide enterprises with work efficiency while mobilizing the enthusiasm of employees through big data. At present, big data is not yet mature, the combination of performance management and big data still needs more in-depth mining and research, and the practicality of performance management information system needs further analysis.

\section{References}

[1] Shang Xin. Discussion on the Innovation of Human Resource Performance Management in Stateowned Enterprises [J]. Chinese and Foreign Entrepreneurs, 2019(19):88-89

[2] Zhao Huijuan Enterprise Performance Management System Reengineering under Innovation Strategy [J]. China Human Resources Development, 2011(01):17-21.

[3] Wang yandan. enterprise performance management in the big data era [J]. operation and management, 2015(12):56-58

[4] Cao Xiaoyan. Several Thoughts on Human Resource Performance Management in Enterprises [J]. Mall Modernization, 2011(05):117

[5] Zhang Xing. ways to improve human resource performance management in small and mediumsized enterprises [J]. China commerce, 2012(11):63-64

[6] Zhuang Zecheng. innovative thinking on human resources management of listed companies under the background of big data [J]. human resources development, 2019(13):72-73

[7] Zhang jingru. research on innovation of enterprise human resource performance management in big data era $[\mathrm{J}]$. China management information

[8] Liu Zhao. A Preliminary Study on Human Resource Performance Management in Big Data Era [J]. China's Management Informatization, 2019,22(08):70-71

[9] Stewart $r$, than OS a, Robert hetal, modeling and improving human decision making with simulation [j]. in proceedings of the 2001 winter simulation conference, 2001. Hua, 2019,22(11):70-72. 